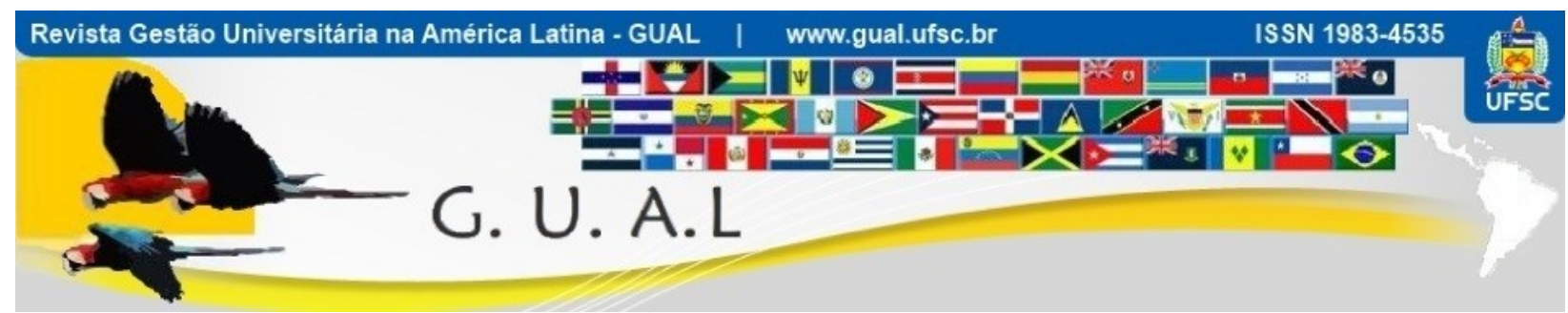

DOI: http://dx.doi.org/10.5007/1983-4535.2017v10n2p189

\title{
FATORES DIFICULTADORES NA FASE PRÉ- IMPLANTAÇÃO DO E-SOCIAL NA CONCEPÇÃO DE INSTITUIÇÕES COMUNITÁRIAS DE ENSINO SUPERIOR DE SANTA CATARINA
}

\author{
DIFFICULT ASPECTS IN THE E-SOCIAL PRE IMPLEMENTATION FASE IN \\ HIGHER EDUCATION COMMUNITY INSTITUTIONS IN SANTA CATARINA
}

Antonio Zanin, Doutor

Universidade Comunitária da Região de Chapecó - UNOCHAPECÓ zanin@unochapeco.edu.br

Odilon Luiz Poli, Doutor Universidade Comunitária da Região de Chapecó - UNOCHAPECÓ odilon@unochapeco.edu.br

Luciane dos Santos Ferreira da Silveira, Especialista Universidade Comunitária da Região de Chapecó - UNOCHAPECÓ lusantos@,unochapeco.edu.br

Rodrigo Barichello, Doutor Universidade Comunitária da Região de Chapecó - UNOCHAPECÓ rodrigo.b@,unochapeco.edu.br

Júlio Adriano Ferreira dos Reis, Doutor Universidade Comunitária da Região de Chapecó - UNOCHAPECÓ julioreis@unochapeco.edu.br

Recebido em 12/outubro/2015

Aprovado em 14/fevereiro/2017

Sistema de Avaliação: Double Blind Review

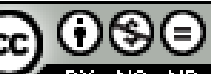

Esta obra está sob uma Licença Creative Commons Atribuição-Uso. 


\title{
RESUMO
}

O controle fiscal brasileiro passa por um processo de mudança, principalmente referente à implementação de novas ferramentas de controle que buscam normatizar a relação entre o fisco e os contribuintes. Uma dessas mudanças é a implementação do EFD-Social, o que tem demandado esforço significativo das organizações, pois trata-se de algo novo, que demanda uma mudança não só de processos, mas, também, de cultura de gestão. Sob esse contexto, o presente estudo objetivou analisar as dificuldades das Instituições Comunitárias de Ensino Superior (ICES) de Santa Catarina, vinculadas à Associação Catarinense das Fundações Educacionais (ACAFE), na adaptação para adesão ao E-Social na fase pré-implantação. A pesquisa se caracteriza como sendo exploratória, descritiva e quantitativa. A amostra é constituída por aproximadamente $60 \%$ da população pesquisada e a coleta dos dados ocorreu por meio de questionários coletados durante os meses de fevereiro a maio de 2015. A análise dos dados revelou que as ICES estão em fases distintas de implementação do EFD-Social. Percebe-se ainda que, na perspectiva das ICES pesquisadas, a implementação do EFD-Social trará mais vantagens do que desvantagens, sugerindo o início de uma mudança cultural das organizações, que passam a perceber o instrumento como uma ferramenta de gestão, e não somente de controle fiscal.

Palavras-chave: EFD-Social. Instituições comunitárias de ensino superior. ACAFE.

\begin{abstract}
Brazilian financial control is changing, mainly because of the implementation of new control tools which try to regulate the relation between the revenue and contributors. One of these changes is the EFD- Social implementation, which the organizations are putting a huge effort, because it is something new, where its demands is not only of processes but also of the management culture. Under this context, this study had as objective analyse the difficulties of the Higher Education Community Institutions - ICES - in Santa Catarina, associated to ACAFE, in the accession adaptation of E-social in the pre implementation fase. The research is exploratory, descritive and quantitative. The sample is composed with about $60 \%$ of the researched population and the data collect was made through questionaries collected from february to may of 2015. The data analysis revealed that ICES are in distintives fases of EFDSocial implementation. It is also possible to verify, in the perspective of the researched ICES, that the EFD-Social implementation will bring more advantages than disadvantages, suggesting the beginning of a cultural change in the organizations, which realize this instrument as a management tool not only financial control.
\end{abstract}

Palavras-Chave: EFD-Social. Higher education community institutions. ACAFE. 


\section{INTRODUÇÃO}

A sociedade tem passado por mudanças constantes e cada vez mais rápidas. Percebese que, a partir da Revolução Industrial, os conhecimentos tecnológicos e a estrutura social foram modificados de forma acelerada, principalmente entre o final do século XX e início do século XXI, em que as informações decorrentes da tecnologia passaram a seguir avanço rápido, gerando informações propiciais e de fácil disseminação no meio social (CARVALHO, 1997). Estes avanços tecnológicos fazem parte da evolução do homem, o que possibilitou progresso na sociedade decorrente de acesso a recursos e propiciaram melhor e maior crescimento profissional. Segundo Bauer (2009), vive-se uma nova sociedade, identificada como sendo a da informação, na qual o conhecimento passou a ser considerado o primeiro recurso, em detrimento da terra, capital e trabalho braçal.

Percebe-se essas mudanças no contexto social e econômico a partir do processo de globalização e do crescimento da importância dada aos adventos relacionados às novas tecnologias, principalmente de informação, em especial a revolução da internet, que vem provocando consideráveis transformações nas organizações. Hoje, ideias rapidamente migram por continentes e países, fronteiras geográficas fragilizam-se, negócios multiplicam-se em variados centros de decisão, a competitividade acirra-se, parcerias são feitas, blocos econômicos são formados, ou seja, não existe limite e nem fronteira para as mudanças. Atualmente, mais do que nunca, paradoxos, contradições e ambiguidades surgem e caem como sendo um processo social natural (BAUER, 2009).

Esse contexto de transformação e mudanças, que envolve o cidadão, o Estado e as organizações, fizeram com que se percebesse que a sociedade estava sofrendo o reflexo dessas mudanças, inclusive em relação aos bons resultados dos negócios, isso advindo também do uso mais intenso e diretivo da tecnologia de informações, que tem como consequência direta a rapidez das informações, sejam no recebimento, sejam no processamento e na emissão. Para Martins et al. (2012), as inovações advindas do desenvolvimento tecnológico fazem com que o conhecimento seja transmitido de uma ponta a outra do mundo em questão de segundos. Com a chegada dessas novas tecnologias, as empresas precisam estar atentas às mudanças constantes; por outro lado, os órgãos fiscalizadores podem aproveitar essa circulação de informações por multimeios, instrumentalizando-se com novas e mais eficazes ferramentas a integração de dados que é possível ser feita. 
Sendo assim, percebe-se que para atuar em um ambiente tão dinâmico, como se apresenta o organizacional/social atual, necessário se faz ser também dinâmico, ou seja, ter capacidade de flexibilidade, para se adaptar rapidamente à realidade que se apresenta em decorrência de qualquer contexto. Ferreira (2006, [s.p.]) afirma que “[...] uma empresa só será dinâmica, mais agressiva e mais atuante que outras na medida em que utilizar de sistemas de informação de ponta e por consequência pessoas capacitadas para manusear tal.”

No caso das Instituições Comunitárias de Ensino Superior, apesar de serem consideradas, conforme aponta Lopes (2004 apud Zanin, 2015), diferenciadas na sua gestão, pois a dinâmica baseia-se em princípios estratégicos, tais como, sustentabilidade, efetividade social e complementaridade, o panorama para gestão não é diferente das organizações tradicionais, ou seja, o ambiente é de mudança e de necessidade de alinhamento e adaptação do processo de gestão com as novas demandas. Segundo Silva (2014, p. 260), “[...] o ambiente das organizações de ensino superior tem se alterado sobremaneira, tanto em nível de macro ambiente, como nível do ambiente de negócio."

$\mathrm{Na}$ esteira dessas mudanças, as entidades governamentais, percebendo a necessidade de se ajustarem a essa "nova" realidade social/econômica, passaram a buscar maior agilidade na utilização da informação. Para isso, procuraram formas de utilizar a seu favor as tecnologias de informações mais avançadas, analisando que, com isso, poderiam passar a ter maior "controle" sobre o contribuinte, inclusive, notificando-o em caso de sonegação ou erros de informações, melhorando, desta forma, a arrecadação de impostos.

Cabe ressaltar que as várias ações já implantadas pelos diversos órgãos do Estado, arrecadadores de tributos, com a boa utilização dos processos de informação e das novas tecnologias, possuem, atualmente, acesso a informações que permitem fiscalizar o contribuinte a partir do cruzamento de informações desse contribuinte, reduzindo dessa forma a necessidade de fiscalizações in loco, fazendo-o apenas em casos mais complexos.

Uma dessas novas ferramentas de fiscalização do Estado Brasileiro, implementada recentemente, foi o Sistema Público de Escrituração Digital (SPED), que foi considerado um avanço na ordenação das informações entre a relação do fisco e os contribuintes. O SPED foi regulado e estabelecido pelo Decreto n. 6.022, de 22 de janeiro de 2007, e alterado pelo Decreto n. 7.979, de 8 de abril de 2013, em conformidade com seu Art. $2^{\circ}$, que unificou as atividades de recepção, validação, armazenamento e autenticação de livros e documentos que integram a escrituração contábil e fiscal dos empresários e das pessoas jurídicas, inclusive as 
isentas, mediante fluxo único, computadorizado, de informações. O SPED, dessa forma, busca controlar e auditar as informações geradas pelas empresas de maneira ágil e fácil, a partir do cruzamento das informações de operações mercantis das organizações.

Como desdobramento do SPED Fiscal e Contábil, que vem obtendo resultados muito satisfatórios, e buscando ainda maior integração de informações para maior capacidade de cruzamento de dados, surge o projeto de Escrituração Fiscal Digital Social (EFD-Social), que consiste na escrituração digital da folha de pagamento e das obrigações trabalhistas, previdenciárias e fiscais, permitindo uma fiscalização muito mais eficaz e rápida no controle da sonegação e se necessário na aplicação de multas ou outras medidas legais cabíveis por lei. O EFD-Social passa a ser, portanto, aplicável a partir da Portaria MF n. 203, de 14 de maio de 2012, tendo em vista o disposto no art. 11 do Decreto Lei $\mathrm{n}^{0} 1.967$, de 23 de novembro de 1982, nos incisos I, III e IV da Lei n. 8.212 de 24 de julho de 1991 e no Decreto n. 6.022, de 22 de janeiro de 2007.

O EFD-Social, ou E-Social, por ser ainda um processo em fase de pré-implementação, tem trazido uma série de dúvidas e expectativas às organizações de uma forma geral, deixando o ambiente dessas organizações em uma condição de insegurança e de busca de informações para melhor responder a essa nova exigência legal. Sendo assim, a presente pesquisa busca investigar essa realidade de incerteza quanto ao E-Social. Tem-se, então, como problema: verificar a realidade da implementação do novo sistema nas organizações, especificamente em Instituições de Ensino Superior Comunitárias do estado de Santa Catarina. Como objetivo principal para este artigo, busca-se investigar quais são os fatores dificultadores presentes nas Instituições Comunitárias de Ensino Superior vinculadas à Associação Catarinense das Fundações Educacionais (ACAFE) para adesão ao E-Social.

Tal pesquisa se mostra relevante, tendo em vista que o tema é recente, se encontra em evidência, e por isso percebe-se a necessidade de informações mais claras em relação ao processo de desenvolvimento, preparo e implementação desse novo sistema nas organizações, pois trata-se de uma exigência legal, portanto, passível de se tornar realidade, estejam as organizações preparadas ou não, em um curto espaço de tempo.

Para melhor desenvolvimento do estudo, este foi dividido em quatro seções distintas desta introdução. A primeira trata do embasamento teórico, onde buscou-se definir o que é SPED e EFD-Social, além de outros conceitos relevantes para esse estudo. Na segunda, buscou-se discorrer a respeito da metodologia científica, esclarecendo sua tipologia e seu 
design. Na terceira seção, são estruturados e analisados os dados coletados. Já na quarta seção apresenta-se a conclusão, onde buscou-se responder ao problema de pesquisa e atender ao objetivo proposto para o artigo. Por fim, apresentam-se descritas as referências bibliográficas utilizadas.

\section{REVISÃO DA LITERATURA}

\subsection{O SISTEMA PÚBLICO DE ESCRITURAÇÃO DIGITAL - SPED}

Acompanhando o processo de transformação social e organizacional acontecido nas últimas décadas no Brasil, a contabilidade vem passando por grandes mudanças desde sua origem. Tudo isso devido ao processo de evolução da tecnologia da informação cada vez mais acessível, e ao mundo globalizado. Segundo Chahin et al. (2004, p. 3): "A telemática - a união das tecnologias de informação e de comunicação eletrônicas digitais e convergentes oferece meios poderosos e cada vez mais baratos de aperfeiçoar nossa democracia, pagar nossa dívida social e estimular nossa economia”. Diante deste cenário, as três esferas de governo - federal, estadual e municipal - cada vez mais se preparam e implementam relevantes avanços para monitoração de tributos. Uma das principais modificações que se tornou alvo de discussões nos últimos anos para os contribuintes e assessores contábeis surgiu com a edição do Decreto n. 6.022, de 22 de janeiro de 2007, publicado no Diário Oficial em edição extra, definindo SPED como:

[...] instrumento que unifica as atividades de recepção, validação, armazenamento e autenticação de livros e documentos que integram a escrituração comercial e fiscal dos empresários e das sociedades empresárias, mediante fluxo único, computadorizado, de informações.

O Sistema Público de Escrituração Digital (SPED) faz parte do Programa de Aceleração do Crescimento do Governo Federal (PAC 2007-2010), constituindo-se em mais um avanço nas relações entre o físco e os contribuintes.

O projeto consiste na modernização da sistemática atual de cumprimento das obrigações acessórias dos contribuintes, utilizando-se da certificação digital dos documentos, garantindo, assim, a validade jurídica desses. Este sistema foi implantado em nível nacional e, com muitas discussões, se torna um sucesso para a transparência nas informações geradas e uma redução nos números de declarações enviadas por parte dos contribuintes, economia nos gastos das empresas e uma redução no tempo (NFe do Brasil, Cartilha SPED BRASIL). 
O SPED foi criado com um conjunto de informação pelo governo, como Escrituração Contábil Digital (ECD), Sped Fiscal, EFD Contribuições, Controle Fiscal de Transição (FCont), Nota Fiscal Eletrônica (NF-e) e Conhecimento Eletrônico de Transportes (CT-e), todos já sendo executados. A Nota Fiscal Eletrônica foi um dos primeiros projetos implantados e executado no SPED, em que substituiu a atual emissão do documento fiscal em papel, com validade jurídica garantida com a assinatura digital (Portaria da NF-e, 2014).

Sobre o conceito de Sistema Público de Escrituração Digital, a Secretaria da Fazenda do Estado de São Paulo dispõe:

\begin{abstract}
A Escrituração Digital é um arquivo digital, que se constitui de um conjunto de escriturações de documentos e de outras informações de interesse das unidades federadas e da Receita Federal do Brasil, bem como de registros de apuração de impostos referentes ás operações e prestações praticadas pelo contribuinte. Este arquivo deverá ser assinado digitalmente e transmitido, via internet, ao ambiente SPED.
\end{abstract}

De acordo com a Secretaria do Estado da Fazenda, entende-se que SPED é ampla, pois abrange elevada quantidade de informações enviadas às administrações tributárias e aos órgãos fiscalizadores.

\title{
2.2 ESCRITURAÇÃO FISCAL DIGITAL SOCIAL - EFD-SOCIAL
}

A partir do Decreto n. 6.022/2007, que instituiu o Sistema Público de Escritura Digital (SPED), a EFD-Social criada a partir do Ato Declaratório Executivo n. 5, de 17 de julho de 2013, publicado no Diário Oficial da União em consonância com a Caixa Econômica Federal, que só aprova e divulga o seu primeiro layout mais tarde. E é da Circular de n. 642, de 6 de janeiro de 2014, que surgiu a escrituração digital da folha de pagamento e das obrigações trabalhistas, previdenciárias e fiscais relativa e qualquer vínculo trabalhista contratados no Brasil.

Este projeto está sendo considerado como mais um avanço na informatização na relação entre o fisco e os contribuintes. Para Carvalho (2013, [s.p.]): "A Escrituração Fiscal Digital da área trabalhista e previdenciária foi batizada - embora ainda não tenha nascido - de EFD-Social, ou também chamada de SPED-Folha (Sistema Público de Escrituração Digital).”

Sampaio (2013) relata que as informações eletrônicas geradas ficarão disponíveis para a fiscalização da Receita Federal, Ministério do Trabalho, Previdência Social e a Justiça Trabalhista, além de ficarem disponíveis também aos trabalhadores de todo o país". 
O principal foco do EFD-Social, mais conhecido como E-Social, é atender as necessidades da Secretaria Federal do Brasil (RFP), do Ministério do Trabalho e Emprego (MTE), do Instituto Nacional do Seguro Social (INSS), da Caixa Econômica Federal (CEF) e do Conselho Curador do Fundo de Garantia por Tempo de Serviço (FGTS), bem como, a Justiça do Trabalho para tratamento das Ações de Reclamatórias Trabalhistas.

O E-Social está ligado ao trabalhador celetista, os prestadores de serviços, autônomos, sócios e acionistas e demais envolvidos em qualquer situação do trabalho e empegados, além das situações encargos previdenciários (Manual de Orientação do E-Social, Versão 1.0).

Sobre o layout do E-Social, a Receita Federal do Brasil em seu sítio na internet dispõe:

As informações que farão parte da EFD-Social são:

- $\quad$ Eventos trabalhistas - informações resultantes da relação jurídica entre o empregado e o empregador, tais como admissões, afastamentos temporários, comunicações de acidente de trabalho, etc.;

- $\quad$ Folha de pagamento;

- Ações judiciais e trabalhistas;

- Retenções de contribuição previdenciárias;

- Algumas contribuições previdenciárias substituídas com as incidentes sobre a comercialização da produção rural, espetáculos desportivos, cooperativas de trabalho, prestação de serviços com cessão de mão de obra, patrocínios as associações desportivas que mantenham equipes de futebol profissional, etc.

Os eventos de movimentação das informações trabalhistas deverão ser transmitidos tempestivamente, ou seja, na medida em que ocorrerem, em arquivos individuais. Cada evento cadastrado alimentará a base de dados na plataforma DE Registro de Eventos Trabalhistas, demostrando todo o histórico laboral do trabalhador. Em contrapartida, todas as entidades ficarão informadas quando o colaborador estiver de aviso de férias, sofre em acidente de trabalho, estar em aviso prévio e até mesmo desligado, não gerando mais fraudes nas datas dos eventos citados.

O Quadro 1 apresenta os objetivos propostos pelo E-Social.

\begin{tabular}{|l|}
\hline Racionalizar e uniformizar as obrigações acessórias para os contribuintes; \\
\hline Reduzir o custo de produção; \\
\hline Controlar e disponibilizar informações trabalhistas, previdenciárias e fiscais; \\
\hline Compartilhamento de um único banco de dados entre os órgãos intervenientes; \\
\hline Melhorar a distribuição da carga tributária sobre os contribuintes pelo vigoroso combate à sonegação; \\
\hline $\begin{array}{l}\text { Reduzir as fraudes na concessão de benefícios previdenciários e no seguro desemprego pela implementação de } \\
\text { métodos seguros de transmissão e cruzamento de informações; }\end{array}$ \\
\hline Ampliar a base de arrecadação dos tributos incidentes sobre a remuneração, sem aumentar a carga tributária; \\
\hline Reduzir a informalidade na relação de emprego; \\
\hline $\begin{array}{l}\text { Identificar a evasão tributária previdenciária e das demais tributações incidentes das relações das organizações e } \\
\text { das pessoas; }\end{array}$
\end{tabular}

Quadro 1 Objetivos do E-Social.

Fonte: Adaptado de Sampaio (2013). 
O projeto, então, prevê reduzir o melhoramento da carga tributária dos contribuintes, pois haverá melhor rigor quanto à sonegação, ampliando a base de arrecadação dos tributos incidentes sobre a remuneração sem ter de aumentar a carga tributária, deixando mais clara a identificação de práticas ilícitas trabalhistas, previdenciárias e tributárias.

Quanto aos prazos do envio, o EFD-Social teve que ser prorrogado por algumas vezes devido a dificuldades encontradas pelas empresas de atender as complexidades exigidas pelo programa disponibilizado. Como se trata de um programa que traz uma série de obrigações e manuseio de informações que a empresa precisa alimentar e cumprir, isso demanda investimento tanto para um sistema operacional que ligue todas estas informações quanto a treinamento dos funcionários para incorporar os dados.

O primeiro layout foi disponibilizado na Versão 1.0, no qual o governo federal estipulou prazo de início da obrigatoriedade, que posteriormente foi prorrogado, em que seria informado o novo prazo após a publicação da nova Versão 1.2 no Manual de Orientação do EFD-Social.

Em 4 de junho de 2014, a Caixa Econômica Federal, através da Circular 657, declara aprovado o novo layout da Versão 1.2 do Manual de Orientação:

Será disponibilizado ambientes de teste para os eventos iniciais, eventos não periódicos e tabelas. E após 6 meses contados a partir dessa disponibilização dos ambientes de testes é que será obrigatório transmissão dos eventos para as empresas de grande e medias, aquelas que possuam faturamento anual de 3.600.000,00 no ano de 2014 e para as demais categorias de empregadores será observado as condições especiais de tratamento diferenciado que apliquem a categoria de enquadramento, como exemplo de casos especiais são os Seguro Especial, Pequeno Produtor Rural, Empregador Domestico, Micro e Pequenas Empresas e Optantes pelo Simples Nacional.

Em decorrência dos atrasos da implantação do E-Social, a Caixa Econômica Federal, na qualidade de agente operador do Fundo de Garantia do Tempo de Serviço (FGTS), no uso das atribuições que lhe são conferidas pelo artigo $7^{\circ}$, inciso II, da Lei 8.036, de 11 de maio de 1990, e de acordo com o Regulamento Consolidado do FGTS, aprovado pelo Decreto n. 99.684, de 8 de novembro de 1990, alterado pelo Decreto n. 1.522, de 13 de junho de 1995, em consonância com a Lei n. 9.012, de 11 de março de 1995, e com o Decreto n. 8.373, de 11 de dezembro de 2014, Resolução n. 1 do Comitê Gestor do E-Social, de 20 de fevereiro de 2015, publica Circular de n. 673, de 25 de fevereiro de 2015. 
Referente aos eventos aplicáveis ao FGTS, declara aprovado o Manual de Orientação do eSocial versão 2.0 (MOS) que define o leiaute dos arquivos que compõem o Sistema de Escrituração Fiscal Digital das Obrigações Fiscais, Previdenciárias e Trabalhistas (eSocial), e que deve o empregador, no que couber, observar as disposições deste manual.

Com esta atualização na legislação, as instituições ganharam um prazo maior para adequação e implantação desta nova tecnológica da informação. Com a Resolução CD/Social n. 01, de 24 de junho de 2015, que dispõe sobre o sistema de escrituração digital das obrigações fiscais, previdenciárias e trabalhistas (E-Social), alterado pelo Comitê Diretivo do E-Social, foi publicado um novo cronograma que varia de acordo com o faturamento e atividade:

I - A transmissão dos eventos do empregador com faturamento no ano de 2014 acima de R\$ 78.000.000,00 (setenta e oito milhões reais) deverá ocorrer a) A partir da competência setembro de 2016, obrigatoriedade de prestação de informações por meio do eSocial, exceto as relacionadas na alínea (b); b) A partir da competência janeiro de 2017, obrigatoriedade da prestação de informação referente à tabela de ambientes de trabalho, comunicação de acidente de trabalho, monitoramento da saúde do trabalhador e condições ambientais do trabalho.

II - A transmissão dos eventos para os demais obrigados ao eSocial deverá ocorrer a) A partir da competência janeiro de 2017, obrigatoriedade de prestação de informações por meio do eSocial, exceto as relacionadas na alínea (b); b) A partir da competência julho de 2017, obrigatoriedade da prestação de informação referente à tabela de ambientes de trabalho, comunicação de acidente de trabalho, monitoramento da saúde do trabalhador e condições ambientais do trabalho $\S 1^{\circ} \mathrm{O}$ tratamento diferenciado, simplificado e favorecido a ser dispensado às microempresas e empresas de pequeno porte, ao Micro Empreendedor Individual (MEI) com empregado, ao empregador doméstico, ao segurado especial e ao pequeno produtor rural pessoa física será definido em atos específicos observados os prazos previstos no caput.

Esta nova divulgação oficial do E-Social será um passo amplo para as instituições melhor se adequarem e começarem a implantação de maneira mais efetiva, levando em consideração os problemas relacionados à atividade diária do departamento pessoal. Por outro lado, após instrumentalizada, essa nova ferramenta poderá apoiar o processo de gestão das ICES, que necessitam mais do que nunca de maior eficiência e adaptabilidade aos "novos tempos". Conforme apontam Nogueira, Garcia e Ramos (2012), conhecimento, competitividade, agilidade, informação, transparência e qualidade surgem como fatores estratégicos para gestão das organizações acadêmicas, especialmente nesse novo cenário cada vez mais interdependente, que caracteriza a sociedade atual. 


\section{PROCEDIMENTOS METODOLÓGICOS}

O presente artigo caracteriza-se como sendo uma pesquisa eminentemente quantitativa, exploratória, descritiva e de levantamento. Considera-se que sua unidade de análise é a organização.

Richardson (1989) afirma que a pesquisa quantitativa caracteriza-se pelo emprego da quantificação, tanto nas modalidades de coleta de informações, quanto no tratamento dessas através de técnicas estatísticas, desde as mais simples até as mais complexas. De acordo com Richardson (1989), este método é frequentemente aplicado nos estudos descritivos.

Já a escolha de desenvolvimento de um estudo de natureza exploratória e descritiva justifica-se pela necessidade do pesquisador em se familiarizar com as pessoas no contexto organizacional e suas preocupações - exploratória -, além de trazer a possibilidade ao estudo de descrever o "como" e "o que" do fenômeno - descritiva (Poupart et al., 2012).

Segundo Silva (2003), a pesquisa exploratória é aquela realizada em área na qual há pouco conhecimento acumulado e sistematizado. Tem como objetivo proporcionar maior familiaridade com o problema, para torná-lo mais explícito ou para construir hipóteses. Assim, a pesquisa busca conhecer com mais profundidade o tema proposto, através da abordagem de questões de pesquisas.

Quanto aos procedimentos, a pesquisa caracteriza-se como levantamento ou survey, por se destacar com a coleta de informações de diversos integrantes do universo pesquisado. Segundo Gil (1999, p. 70), a pesquisa de levantamento, basicamente, procede-se a solicitação de informações a um grupo significativo de pessoas acerca do problema estudado para, em seguida, mediante análise qualitativa e quantitativa, obter as conclusões correspondentes aos dados coletados.

Os dados utilizados no presente estudo, que se caracterizam com sendo primários, tiveram como instrumento de coleta questionários estruturados, que foram enviados via e-mail para as Instituições de Ensino Superior associadas à ACAFE. Este questionário estruturado foi constituído por perguntas do tipo abertas e fechadas.

Esse questionário continha 14 questões e estava divido três partes distintas: a primeira com questões gerais referentes à Instituição e à formação do gestor; a segunda formada por questões referentes às dificuldades encontradas na fase pré-implantação do E-Social, pois a atividade relacionada ao ensino se difere de empresas comerciais e industriais, pois precisam efetuar ajustes internos para adaptarem-se a novas mudanças; por fim, a terceira parte buscava 
identificar as principais dificuldades encontradas no momento da implantação do E-Social, as quais podem ocorrer em função de sistemas, ou mesmo de cumprimento da Legislação trabalhista vigente. Para tanto, utilizou-se da escala likert de 5 pontos, em que o respondente atribuiu nota de 1 a 5 de acordo com o grau de importância, sendo os extremos: 1 pouco importante e 5 muito importante. Essa escala indica, em nível de concordância dos respondentes, onde a maior média corresponde a maior concordância.

A população da pesquisa foi composta de gestores da área de Recursos Humanos das 13 Instituições de Ensino Superior pertencentes à ACAFE. A seleção das Instituições de Ensino Superior associadas à ACAFE se deu pelo fato de que estas, normalmente, possuem maior dificuldades para adaptar-se às legislações vigentes, de modo especial ao E-Social, que demanda mudança de cultura interna, no que tange ao registro de funcionários. Outro ponto relevante a ser considerado é o fato que várias ICES ofertam cursos nos três turnos diários, dificultando a distribuição de carga horária para os professores, pois precisam manter o tempo de descanso, atendendo ao disposto na CLT.

Dessa população, a amostra considerada para o estudo foi de sete ICES, que foi o número de Instituições que enviaram aos pesquisadores os questionários completamente respondidos, dentro do prazo estabelecido para coleta de dados. Esse número corresponde a aproximadamente $55 \%$ da população, o que é considerado uma amostra relevante.

\section{ANÁLISE DOS RESULTADOS}

Neste tópico, são apresentados os resultados obtidos a partir da análise dos dados coletados com as Instituições de Ensino Superior associados à ACAFE. Essa análise considerou todas as respostas dos questionários válidos, utilizando como apoio as medidas estatísticas desenvolvidas a partir da utilização do Excel, sendo as principais medidas consideradas a média e a frequência das respostas obtidas.

Quanto ao perfil dos respondentes, que são os responsáveis pela área de Recursos Humanos das Instituições que compõem a amostra, pôde-se aferir que: 57\% são do sexo feminino e $43 \%$ são do sexo masculino; quanto a idade, $29 \%$ tem entre 34 e 41 anos e $71 \%$ acima de 42 anos; quanto ao nível de escolaridade, 100\% dos respondentes possuem especialização, sendo que as suas áreas de formação são: $86 \%$ dos respondentes são formados em Administração de empresas e 14\% em Direito. 
Tabela 1 Cargo/função que ocupa na organização.

\begin{tabular}{lll}
\hline Cargo/Função & Frequência Absoluta & Frequência Relativa \\
\hline Auxiliar & 0 & $0 \%$ \\
Assistente & 0 & $0 \%$ \\
Analista & 1 & $14 \%$ \\
Técnico & 0 & $0 \%$ \\
Supervisor & 0 & $0 \%$ \\
Coordenador & 2 & $29 \%$ \\
Gerente & 3 & $43 \%$ \\
Diretor & 1 & $14 \%$ \\
Outros & 0 & $0 \%$ \\
\hline Total & $\mathbf{7}$ & $\mathbf{1 0 0 \%}$ \\
\hline
\end{tabular}

Fonte: Dados da pesquisa.

Sendo assim, pode inferir que, em relação ao perfil dos respondentes, que trata-se de um público que a maioria já possui experiência profissional, pois estão acima dos 42 anos e tem boa formação acadêmica, que inclusive está alinhada às áreas congêneres da função praticada. Isso é um dos fatores que são percebidos como preponderantes para menor dificuldade para implementação do E-Social.

Em relação ao cargo que ocupa na organização, verifica-se na Tabela 1 que, dentre os pesquisados, 14\% são analistas, 29\% coordenadores, $43 \%$ gerentes e $14 \%$ diretores.

Isso demonstra que as IES estão dando relativa importância ao processo de implementação do E-Social, pois designou, na maioria das organizações pesquisadas, responsabilidade para pessoas que possuem cargos de relativa influência na estrutura organizacional, o que pode diminuir as resistências naturais a esse tipo de processo, que necessitará de mudanças no próprio processo de gestão dessas organizações.

Quanto ao tempo de conhecimento do E-Social, a Tabela 2 mostra que $86 \%$ dos respondentes tomaram conhecimento sobre a necessidade de implantação do E-Social há mais de 2 anos, enquanto 14\% responderam que tomaram ciência dessa nova legislação entre 1 e 2 anos. Os resultados permitem analisar que provavelmente algumas Instituições podem estar menos preparadas para promover as mudanças internas no sentido de preparar a empresa para a implantação do E-Social, pois o tempo destinado ao entendimento da legislação, e planejamento e estruturação dos processos decorrentes do E-Social, pode ser considerado curto. 


\section{FATORES DIFICULTADORES NA FASE PRÉ-IMPLANTAÇÃO DO E-SOCIAL NA CONCEPÇÃO DE INSTITUIÇÕES COMUNITÁRIAS DE ENSINO SUPERIOR DE SANTA CATARINA \\ DOI: http://dx.doi.org/10.5007/1983-4535.2017v10n2p189}

Tabela 2 Há quanto tempo você tomou ciência sobre a EFD-Social.

\begin{tabular}{lll}
\hline Dados & Frequência Absoluta & Frequência Relativa \\
\hline Não sei do que se trata & 0 & $0 \%$ \\
Há menos de um mês & 0 & $0 \%$ \\
Entre 2 e seis meses & 0 & $0 \%$ \\
Entre 6 meses e 1 ano & 0 & $0 \%$ \\
Há mais de 1 ano & 1 & $14 \%$ \\
Há mais de 2 anos & 6 & $86 \%$ \\
\hline Total & $\mathbf{7}$ & $\mathbf{1 0 0 \%}$ \\
\hline
\end{tabular}

Fonte: Dados da pesquisa.

A preocupação com o entendimento acerca do E-Social fica evidente quando questiona-se aos pesquisados sobre sua participação em cursos de formação sobre o E-Social: $100 \%$ dos respondentes afirmaram ter participado de cursos de capacitação. Isso referência que as IES estão preocupadas com os ajustes internos necessários, bem como, com identificação das mudanças que antecedem a implantação do E-Social.

Complementando à questão sobre participação em cursos para desenvolvimento sobre E-Social, perguntou-se sobre o número de cursos/eventos de capacitação em que os respondentes participaram. Os dados iniciais revelam que todos os respondentes afirmaram que haviam participado de algum desenvolvimento sobre o tema, o que sumariamente sugere que já tinham conhecimento sobre o assunto, ou seja, estavam devidamente capacitados a conduzir o processo de planejamento e implementação do E-Social em sua organização. Porém, ao analisar a quantidade de cursos/formação realizadas pelos respondentes, verificouse que $15 \%$ participaram de uma capacitação, 29\% participaram em 2 formações, 14\% participaram de três formações e que $42 \%$ participaram de 4 ou mais cursos/formações.

Esses dados permitem analisar, de maneira mais aprofundada, que uma parcela significativa das IES (34\%) pode estar investindo pouco tempo e recursos na formação/aprimoramento dos profissionais que atuam/atuarão com o E-Social, pois tais profissionais participaram até o momento da pesquisa, no máximo, de 2 cursos voltados para aprimoramento do conhecimento em relação ao tema. Esse dado possibilita, inclusive, questionar se a falta de preparo/desenvolvimento dos quadros funcionais não pode, de alguma forma, comprometer a capacidade de planejamento e implementação das ações decorrentes do E-Social.

Quanto às entidades onde as IES buscam apoio para formação/aprimoramento de seu quadro funcional para melhor entendimento e desenvolvimento dos processos relativos ao ESocial, a Tabela 3 revela que: 29\% buscaram capacitação na ACAFE, sendo que esta entidade 
promoveu 2 cursos de capacitação às suas associadas; $23 \%$ efetuaram capacitação organizada pela própria Instituição, o que demonstra a preocupação dessas em socializar o conhecimento sobre o tema para um número maior de pessoas; $18 \%$ buscaram capacitação com empresas produtoras ou representantes de software, demonstrando a preocupação dessas, pois acabam interagindo diretamente com o setor de recursos humanos das empresas, tendo em vista o envio das informações para os órgãos fiscalizadores; percebe-se, ainda, que a associação comercial tem ofertado cursos na área, cumprindo com o seu papel junto aos seus associados.

Quanto a oferta e participação em cursos de formação, chama a atenção a falta de oferta/participação em cursos de formação/aprimoramento, por parte da Receita Federal do Brasil, pois trata-se de ator relevante nesse processo de implementação do E-Social.

Ao verificar a modalidade de oferta dos cursos de formação/aprimoramento, percebeuse uma preferência nítida pelos cursos presenciais, sendo que todos os respondentes disseram ter participado de cursos de natureza. Isso pode ser compreendido como sendo decorrente da natureza da formação necessitada e buscada, pois, por se tratar de algo novo, precisa ser compreendido e testado na prática e in loco no sistema.

Tabela 3 Em complemento a pergunta anterior, quais foram as entidades responsáveis pelos cursos de formação participados.

\begin{tabular}{lll}
\hline Dados & $\begin{array}{l}\text { Frequência } \\
\text { Absoluta }\end{array}$ & $\begin{array}{l}\text { Frequência } \\
\text { Relativa }\end{array}$ \\
\hline Receita Federal & 0 & $0 \%$ \\
Sebrae & 0 & $0 \%$ \\
Conselho Regional de Contabilidade & 1 & $6 \%$ \\
Senac & 0 & $0 \%$ \\
Associação Comercial & 2 & $12 \%$ \\
Ministério do Trabalho e Emprego & 1 & $6 \%$ \\
Organização de ensino (universidade, faculdade, etc.) & 4 & $23 \%$ \\
Empresa produtora ou representante de software & 3 & $18 \%$ \\
Acafe & 5 & $29 \%$ \\
Outros & 1 & $6 \%$ \\
\hline Total & $\mathbf{1 7}$ & $\mathbf{1 0 0 \%}$ \\
\hline
\end{tabular}

Fonte: Dados da pesquisa.

Quanto à utilização de fontes para obtenção de informações sobre o EFD-Social, verificou-se que: $31 \%$ dos respondentes buscaram como fonte de informações o site oficial do programa ( $\underline{\text { www.esocial.gov.br) }}$; 31\% buscaram informações a partir da participação em palestras e eventos sobre o tema; 19\% buscaram informações por meio de consultorias especializadas sobre o assunto; 13\% buscaram outras fontes não oficiais, como blogs, sites, 
jornais, revistas etc.; e 6\% usaram o Conselho Regional de Contabilidade como fonte de informações sobre o EFD-Social.

Isso faz com que haja a percepção de que, por tratar-se de um tema complexo e relativamente recente, tendo em vista o elevado número de informações a ser repassado por meio do E-Social, há uma necessidade das Instituições se adaptarem à nova realidade, pois esse ramo de atividade possui especificidades que diferem do comércio e indústria, tendo maior trabalho na fase pré-implantação.

Com o intuito de verificar a questão relativa aos prazos para implantação do E-Social, já que se trata de um fator crítico de sucesso para implementação de um projeto dessa proporção, verifica-se que, dentre os respondentes, $71 \%$ afirmam que o tempo para adequação e implantação do EFD-social é insuficiente, enquanto $29 \%$ consideram o prazo suficiente. Essa diferença de percepção pode ser decorrente de fatores, como tamanho e estrutura organizacional da instituição, preparo das pessoas para implementação das ações relativas ao E-Social, dificuldade em obter informações, falta de uma rede de troca de experiências relativas ao processo de implementação do E-Social, dentre outras.

O levantamento realizado pela pesquisa, em relação aos principais fatores que impactam na implementação do E-Social nas IES pesquisadas, demonstrados na Figura 1, mostram que: a necessidade de se constituir grupos de trabalho multidisciplinares, envolvendo diferentes áreas, inclusive com a participação de atores externos com sindicatos, é percebido com um dos fatores mais relevantes, pois apresenta a maior média de concordância dos respondentes; os fatores vinculados da questões decorrentes de legislação trabalhista (horários, distribuição de carga horária docente e atestados médicos) são apontados como fatores de significativo impacto, apresentando médias de concordância acima de 4 . 


\begin{tabular}{|l|r|r|}
\hline \multicolumn{1}{|c|}{ Respondentes } & \multicolumn{1}{|c|}{ Media } & Desvio Padrão \\
\hline As ações decorrentes da EFD-Social foram devidamente planejadas & 1,857142857 & 1,069044968 \\
\hline $\begin{array}{l}\text { As pessoas responsáveis pelos processos da EFD-social na organização } \\
\text { estão devidamente preparadas para sua operacionalização. }\end{array}$ & 2,571428571 & 1,272418021 \\
\hline $\begin{array}{l}\text { Os processos serão implementados dentro dos prazos formais } \\
\text { estipulados }\end{array}$ & 3,000000000 & 1,154700538 \\
\hline A organização está preparada para implementação do EFD-Social & 2,571428571 & 0,786795792 \\
\hline $\begin{array}{l}\text { A gestão da organização tem consciência da EFD-Social e seus impactos } \\
\text { na gestão da Organização }\end{array}$ & 3,571428571 & 0,786795792 \\
\hline $\begin{array}{l}\text { As áreas envolvidas na implementação da EFD-Social estão preparadas } \\
\text { para as mudanças nos seus processos }\end{array}$ & 2,714285714 & 1,112697281 \\
\hline $\begin{array}{l}\text { A gestão da organização tem consciência da EFD-Social e seus impactos } \\
\text { na gestão da Organização }\end{array}$ & 3,571428571 & 1,133893419 \\
\hline $\begin{array}{l}\text { Necessário um Grupo de trabalho formado por pessoas de vários } \\
\text { setores, inclusive sindicato da classe }\end{array}$ & 4,571428571 & 0,534522484 \\
\hline Dificuldade cumprimento horário, escalas de trabalho & 4,285714286 & 1,253566341 \\
\hline $\begin{array}{l}\text { Adequação jornada de trabalho dos docentes, devido às oscilações } \\
\text { durante os meses/semestres }\end{array}$ & 4,428571429 & 1,133893419 \\
\hline $\begin{array}{l}\text { Cumprimento de prazos na entrega de atestados e exames admissionais e } \\
\text { periódicos }\end{array}$ & 4,428571429 & 1,133893419 \\
\hline $\begin{array}{l}\text { Resistência de docentes em adaptar-se às mudanças e regras } \\
\text { estabelecidas }\end{array}$ & 3,857142857 & 0,899735411 \\
\hline
\end{tabular}

Figura 1 Fatores para implementação de ações do E-Social.

Fonte: Dados da pesquisa.

Também pode ser considerado como fator de forte impacto, com base nas respostas obtidas dos pesquisados, a falta de planejamento das ações decorrentes do E-Social, pois apresenta uma baixa média de concordância. Outro fator de relevância para o processo de implementação do E-Social no âmbito das IES pesquisadas é a existência de resistência por parte do quadro docente em relação a mudanças e regras estabelecidas, que terão impacto por conta da legislação pertinente ao E-Social. Um fator de impacto percebido, que pode ser considerado como sendo positivo, é o de que a gestão da organização tem consciência da EFD-Social e seus impactos na gestão da Organização. Isso significa que, apesar dos desafios e dificuldades, a direção das organizações está sensibilizada na adequação organizacional para implementação da nova sistemática de controle físcal. Outro fator de influência, já citado anteriormente, e aqui reforçado, é a questão do prazo para implementação do E-Social. Assim como antes, aqui percebe-se que os prazos causam preocupação e insegurança quanto à capacidade das organizações de cumprir os prazos legislatórios. 


\section{FATORES DIFICULTADORES NA FASE PRÉ-IMPLANTAÇÃO DO E-SOCIAL NA CONCEPÇÃO DE INSTITUIÇÕES COMUNITÁRIAS DE ENSINO SUPERIOR DE SANTA CATARINA \\ DOI: http://dx.doi.org/10.5007/1983-4535.2017v10n2p189}

Ao analisar, portanto, as médias de concordância obtidas pelos respondentes das ICES, percebe-se que alguns itens ainda não foram trabalhados adequadamente, ou seja, são percebidos como ainda não sendo positivos, dentre os quais destaca-se: o planejamento de ações visando preparar a empresa para implantação do E-Social, e o fato de que as pessoas responsáveis pela implantação do E-Social, além da Instituição e das áreas envolvidas na implementação, ainda não estarem totalmente preparadas para tal. Como fatores, podem ser destacados que: as ICES sentem a necessidade de ter grupos de trabalho de vários setores; reconhecem a necessidade de ajustes a legislação trabalhista.

Ao analisar os dados referentes aos impactos positivos decorrentes diretamente da implementação da EFD-Social, obteve-se o seguinte, conforme demonstrado na Figura 2.

\begin{tabular}{|l|r|r|}
\hline \multicolumn{1}{|c|}{ Respondentes } & \multicolumn{1}{c|}{ Media } & Desvio Padrão \\
\hline A implementação da EFD-Social tornará a gestão mais eficiente & 3,571428571 & 0,786795792 \\
\hline A EFD-Social tornará a gestão mais clara & 3,571428571 & 0,786795792 \\
\hline $\begin{array}{l}\text { A implementação da EFD-Social será um divisor de águas na gestão da } \\
\text { organização }\end{array}$ & 3,714285714 & 0,755928946 \\
\hline $\begin{array}{l}\text { Os processos vinculados ao RH serão aprimorados a partir da EFD- } \\
\text { Social }\end{array}$ & 4,000000000 & 0,577350269 \\
\hline $\begin{array}{l}\text { As vantagens são maiores que as desvantagens pela implementação da } \\
\text { EFD-Social. }\end{array}$ & 3,285714286 & 1,112697281 \\
\hline
\end{tabular}

Figura 2 Impactos decorrentes da implementação da EFD-Social.

Fonte: Dados da pesquisa.

Verifica-se que todos os respondentes entendem que a implementação do EFD-Social trará impactos positivos para a organização, sendo que a média da escala de concordância ficou em torno de 3,5, o que significa que há uma pré-disposição para perceber as proposições feitas pela pesquisa adequadas com a realidade das organizações pesquisadas.

Sendo assim, concorda-se que a implementação do EFD-Social irá contribuir para melhoria dos processos de RH da organização, além de tornar o processo de gestão organizacional mais claro e eficiente, citando, inclusive, que tal processo e implementação poderá ser um “divisor de águas” para essas organizações.

Essa percepção pode ser percebida como sendo interessante, pois trata-se o EFDSocial de um processo que impactará em mudança nos processos de gestão, e isso poderia ser visto com certa resistência. Segundo Nogueira, Garcia e Ramos (2012), a Universidade é uma organização com tendências ao conservadorismo por excelência, podendo sua gestão ser compreendida como essencialmente tradicionalista, burocrática e governamental, tornando-a 
resistente à mudança e à aplicação de novos modelos organizacionais. Entretanto, o presente estudo mostra que as Instituições Comunitárias de Ensino Superior são mais flexíveis a mudanças e sujeitas a novas ferramentas de gestão que os demais tipos de IES.

\section{CONCLUSÕES E RECOMENDAÇÕES}

O EFD-Social é um projeto do Governo Federal que complementa outros existentes no sentido de agilizar o repasse de informações das empresas aos órgãos fiscalizadores, para reduzir a sonegação fiscal. No caso específico do EFD-Social, refere-se a informações trabalhistas, além de informações da contratação de serviços por terceiros, que propiciarão maior controle e facilitarão a fiscalização por parte do Ministério do Trabalho.

Assim sendo, o objetivo do presente estudo foi levantar quais os fatores dificultadores encontrados pelas Instituições Comunitárias de Ensino Superior de Santa Catarina, filiadas à ACAFE, na fase anterior à implantação do E-Social.

Os resultados demonstram que as organizações têm investido de maneira distinta na preparação das pessoas responsáveis pelo desenvolvimento das ações e processos decorrentes da futura implementação do E-Social.

Percebe-se que há uma preocupação dos gestores em buscar qualificação sobre o tema de estudo, dentre os quais $86 \%$ conhecem o assunto a mais de 2 anos, e $95 \%$ dos respondentes efetuaram no mínimo 2 cursos de capacitação, os quais ocorreram de forma presencial.

Os achados da pesquisa apontam que algumas ICES ainda precisam melhorar a informação interna acerca do assunto, pois, em função das especificidades do tipo de atividade desenvolvida, torna-se necessário um trabalho de ajustes na fase pré-implantação.

Pode-se concluir também que os principais fatores percebidos como influenciadores do processo de implementação do E-Social são decorrentes da adequação à legislação trabalhista, da falta de planejamento e adequação da gestão para as mudanças decorrentes no "novo" processo de fiscalização e da resistência dos quadros de pessoal em relação às mudanças necessárias decorrentes desse novo processo de fiscalização.

Por fim, os resultados da pesquisa apontam também em direção à acreditação de que a implementação da EFD-Social trará resultados positivos para gestão da ICE, como: melhoria dos processos de gestão do RH, mais transparência do processo de gestão, dentre outros.

Percebe-se, portanto, que em função da necessidade e diante da ameaça de multas legislatórias, há uma disposição maior para o cumprimento das leis trabalhistas, dentre as 
quais, aprimorar os processos do RH, gestão mais eficiente, adequação dos horários, que são ações estimuladas a partir dos princípios reguladores do EFD-Social.

\section{REFERÊNCIAS}

BAUER, R. Gestão da Mudança: caos em complexidade nas organizações. 1. ed. São Paulo: Atlas, 2009.

CARVALHO, M. G. Tecnologia, desenvolvimento social e educação tecnológica. Revista Educação \& Tecnologia. Curitiba: Centro Federal de Educação Tecnológica do Paraná, jul. 1997.

CARVALHO, Z. EFD-Social: avise na empresa do seu vizinho para mudar já! 2013.

Disponível em:

$<$ http://www.zenaidecarvalho.com.br/index.php?option=com_content\&view=article\&id $=484$ : artigo $22052013 \&$ catid $=35$ :artigos\&Itemid $=6>$. Acesso em: 9 out. 2014.

CAIXA ECONÔMICA FEDERAL. Circular 642 de 04 de Julho de 2014. Disponível em: $<$ http://www.normaslegais.com.br/legislacao/circular-caixa-657-2014.htm>. Acesso em: 8 out. 2014.

Circular 657 de 06 de Janeiro de 2014. Disponível em:

$<$ http://www.normaslegais.com.br/legislacao/circular-caixa-642-2014.htm>. Acesso em: 8 out. 2014.

CHAHIN, A. et al. E-gov.br: a próxima revolução brasileira. São Paulo: Prentice Hall, 2004.

BRASIL, Decreto de n. 6.022, de 22 de Janeiro de 2007. Brasília, 2007. Disponível em: $<$ http://www.receita.fazenda.gov.br/legislacao/decretos/2007/dec6022.htm>. Acesso em: 4 out. 2014.

Decreto de n. 7.979, de 08 de Abril de 2013. Brasília, 2013. Disponível em:

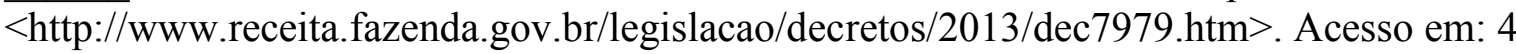
out, 2014.

Ministério da Fazenda. Apresentação do Sistema Público de Escrituração Digital. Brasília, 2012. Disponível em: <http://www1.receita.fazenda.gov.br/sobre-oprojeto/apresetacao.htm>. Acesso em: 4 out. 2014.

Ministério da Fazenda. Portal Nacional da Nota Fiscal Eletrônica. Brasília, 2014. Disponível em: <http://www1.receita.fazenda.gov.br/>. Acesso em: 9 out. 2014.

FERREIRA, L. R. A importância das informações no processo de tomada de decisões. 2006. Disponível em: <http://www.administadores.com.br/artigos/economia-e-financas/aimportancia-das-informacoes-no-processo-de-tomada-de-decisoes/12714/>. Acesso em: 14 out. 2014. 
GIL, A. C. Métodos e técnicas de pesquisa social. 5. ed. São Paulo: Atlas, 1999.

LOPES DE SÁ, A. Teoria da Contabilidade. 5. ed. São Paulo: Atlas, 2010.

MARTINS, P. L. et al. Sped: Sistema Público de Escrituração Digital na Visão do Profissional Contábil. In: Simpósio de Excelência em Gestão e Tecnologia, 9., 2012, Rezende. Anais... Rezende, 2012.

NOGUEIRA, M. G. S. S.; GARCIA, T. E. M.; RAMOS, M. G. G. Governança corporativa, responsabilidade social: a visão de atores de uma Instituição de Ensino Superior - IES FEDERAL. Revista GUAL, Florianópolis, v. 5, n. 3, p. 222-244, dez. 2012.

RAUPP, F. M.; BEUREN, I. M. Metodologia da pesquisa aplicável às ciências contábeis sociais. In: BEUREN, I. M. (Org.). Como elaborar trabalhos monográficos em contabilidade: teoria e prática. 3. ed. São Paulo: Atlas, 2010. p. 76-97.

RECEITA DO BRASIL. Sistema Público de Escrituração Digital. 2014. Disponível em: $<$ http://www.receita.fazenda.gov.br/Sped $>$. Acesso em: 6 out. 2014.

RICHARDSON, R. J. Pesquisa social: métodos e técnicas. São Paulo: Atlas, 1989.

SAMPAIO, F. Apostila E-Social 2013. 2013. (Curso ministrado pela Meta Cursos e Treinamentos 2013).

SILVA, A. C. R. Metodologia aplicada à contabilidade. São Paulo: Atlas, 2003.

SILVA, A. H. et al. Mudanças estratégicas em Universidade Comunitária: um estudo desenvolvido no Rio Grande do Sul. Revista GUAL, Florianópolis, v. 7, n. 1, p. 257-273, jan. 2014.

SILVA, C. F. Percepções dos usuários dos sistemas contábeis nos escritórios de contabilidade confrontando com a visão do programador. $2003.81 \mathrm{f}$. Monografia (Graduação em Ciências Contábeis) - Universidade do Vale do Itajaí, Biguaçu, 2003.

ZANIN, A. et al. Definição de Painel de Indicadores de Desempenho para Instituições Comunitárias de Ensino Superior. Revista GUAL, Florianópolis, v. 8, n. 2, p. 01-27, maio 2015. 